V.M. Zolotaryov, Yu.P. Antonets, S.Yu. Antonets, O.V. Golik, L.A. Shchebeniuk

\title{
ONLINE TECHNOLOGICAL MONITORING OF INSULATION DEFECTS IN ENAMELED WIRES
}

In this paper the authors used non-destructive technological monitoring of defects insulation enameled wire with poliimid polymer. The paper is devoted to the statistical method for processing, comparison and analysis of results of measurements of parameters of insulation of enameled wire because of mathematical model of trend for application in active technological monitoring is developed; the recommendations for parameters of such monitoring are used. It is theoretically justified and the possibility of determination of dependence of the error on the velocity of movement of a wire for want of quantifying of defects in enameled insulation by non-destructive tests by high voltage. The dependence of average value of amount of defects for enameled wire with two-sheeted poliimid insulation in a range of nominal diameter $0.56 \mathrm{~mm}$ is experimentally determined. The technological monitoring purpose is to reduce the quantifying defects of enameled insulation. References 10, figures 5. Key words: enameled wire, poliimid insulation, defects of insulation, technological monitoring, tests by voltage.

Представлены результаты неразрушающего технологического контроля количества дефектов в изоляции эмаль провода на основе полиимидного полимера. Рассмотрено применение статистического анализа результатов измерения показателей контроля с помощью математической модели тренда для использования результатов в активном технологическом контроле. Предложены рекомендации для практического использования параметров функции тренда для контроля гарантированного уровня бездефектности изоляции методами статистики предельных значений. Параметром тренда является скорость уменьшения (или увеличения) длины провода с заданной дефектностью в течение технологического цикла. Теоретически показана и подтверждена измерениями возможсность количественной оценки тенденции изменения дефектности эмальизоляции для провода ПЭЭИДХ2 200 с двухслойной полиимидной изоляцией номинальным диаметром 0,56 мм в течение технологического цикла. Определение количественной оценки тенденции изменения дефектности эмаль изоляции позволяет также выделить и количественно оценить случайную ошибку технологического процесса - суммарную ошибку результатов технологического контроля, которая является количественной характеристикой случайной составляющей стабильности технологического процесса и обусловлена большим количеством причин, каждой из которых можно пренебречь по сравнению с суммой. Библ. 10, рис. 5.

Ключевые слова: эмаль провод, полиимидная изоляция, дефектность изоляции, технологический контроль, испытания напряжением.

Problem definition. The enamel wire based on polyimide synthetic copolymers with a temperature index of $200{ }^{\circ} \mathrm{C}$ has high electrical and mechanical properties of insulation $[1,2]$. The introduction of such innovative types of cable and wire products into production allows to provide the highest modern level of electrical, mechanical strength and heat resistance of the winding insulation of windings of electric machines and apparatuses - mass production of electric machinery.

To manufacture such wires, modern automatic lines with high velocities (up to $1000 \mathrm{~m} / \mathrm{min}$ ) and deep catalytic annealing of enamel lacquers are used [2]. The development of such products, innovative for a specific manufacturer, requires the application of an operational technological control system that ensures the liquidity of products at the reached level of technical parameters. At the same time, control and analysis of the dispersion of the main technical parameters of the products are basic information for the implementation of the principle of continuous quality improvement in accordance with ISO 9001: 2015.

The problem for a specific manufacturer is the development and implementation of non-standard technical and organizational solutions for technological control, with mandatory binding of the technical parameters to the achieved level of production technology. There is a contradiction between the relatively high cost of innovative products, the production of which is based on the use of modern advanced technologies and materials, on the one hand, and the need to organize technological control of the dispersion of technical parameters in the process of a continuous automatic technological cycle that requires additional costs on the other.

The task, at first glance, seems to be one that does not have a solution for the producers in the period of development of products known in the world, but innovative for them. An example is the well-known concept of «Six Sigma» («6б») [3]. In it, the main criterion of product quality is its homogeneity, which is quantitatively reflected by the generally accepted characteristic of the spread of parameters - their rootmean-square deviation $\sigma$. The indicator of homogeneity used in marketing is the ratio of the range of admissible values of the main parameter to the experimentally determined value of $\sigma$. The concept of «Six Sigma Methodology» is a demonstration of the manufacturer's achievements in the quality industry, but does not contain a methodology for ensuring these achievements. 
The presented example shows that the contradiction between the relatively high cost of innovative products and the need for additional costs to organize technological control of the innovative process of its production is one of the main problems of technological development of the enterprise. And the more the technological cycle is automated, the more this problem becomes actual. At the same time, its solution requires the adoption of non-standard technical and technological solutions, since there is a significant theoretical and technical difference between the tasks of acceptance and current technological control [4]. The problem of the organization of active technological control is conceptual for a modern, mass productionoriented, development and automation company.

Analysis of literature. Since this problem is closely related to the economic component of mass production, it was proposed in [1] to resolve the contradictions between the relatively high cost of production and the price factor, as a criterion for liquidity for wires with polyimide insulation, by reducing the level of breakdown voltage requirements agreed with the consumer. In our opinion, the introduction of a spectrum of technical requirements for the same products significantly expands the range of applicable technical requirements. This, at least, blurs the ranges of acceptable values for the parameters of the same product, complicates the relationship between the manufacturer and the customer of the product, but does not solve the problem of applying effective technological control.

The first conceptual works devoted to the tasks of current technological control are dated to the beginning of the $60 \mathrm{~s}$ of the 20th century. And their result is formulated in [5]: «Unlike the acceptance control, where the degree of suitability of ready-made batches of products is determined, current monitoring should ensure the normal course of the technological process.» This means that in the very formulation of the issue of technological control, the possibility of changes in the technological process and the need for rapid detection and quantification of such changes are laid. Theoretically, this means that each regular result obtained during technological control is an element of a different, unknown statistical array. Therefore, the statistical procedure for processing the results of technological control requires the development of an algorithm for processing and presenting the results; Algorithm of decision making. The above general concept of technological control [4] is relevant. Its specific implementation in automated and high-speed continuous technological cycles of modern cable production requires, in addition to almost instantaneous efficiency (on-line mode) $[2,3,5]$ solutions to a number of problems: scientific and technical.

Scientific problems are caused by the following.

Measuring the variance of a technical parameter in the production process by the method of obtaining and presenting the results is mediated and relative. The classical (canonical) measurement model can not be applied to these measurements, since it requires the fulfillment of three conditions [3]:

- the measurement time is unlimited;

- the measured value keeps the true value unchanged during the entire measurement cycle;

- all the factors affecting the result are precisely defined.

At least the first two conditions can not, in principle, be met when measuring the dispersion of a technical parameter in a specific task of the current process control. Therefore, in this case, only a statistical model is acceptable, in which the measured quantity is a sequence of values that give information about the current state of the measurement object. In this case, the true value of the quantity may remain undefined at a given interval of the measurement process [2].

Therefore, in each continuous technological process, it is necessary to develop a statistical model of a specific technological control process, which includes: a statistical model of the process of measuring variance of parameters, an algorithm for processing and presenting the results.

Technical problems are caused by the fact that on the basis of the analysis of the influence of the components of the technological process on the formation of the electrophysical parameters of the product, the following are need:

1) the choice of operations, which are decisive for ensuring the quality of products;

2) selection of measured parameters, which are decisive for ensuring product quality;

3) determining process tolerances for the selected parameters;

4) determining the periodicity of measurements and the minimum sample size.

In this case, it is necessary to divide the trend of the change in the control parameter as a function of the technological time and the random error of the technological process. This separation can be performed according to a known statistical trend model with an error (only the error is a random variable) for a number of observations of the values of the quantity $x[7]$ :

$$
x_{i}=f\left(t_{i}\right)+\delta_{i},
$$

where $t_{i}$ is the deterministic variable, which is the technological time; $f\left(t_{i}\right)$ is the deterministic function (trend of the technological process); $\sigma_{i}$ is the random variable (random component of process stability).

World manufacturers of equipment for enamel wires based on polyimide synthetic copolymers [3] use modern highly efficient systems for continuous statistical monitoring of the specific number of defects (er) of insulation on-line for current process control. The number of defects is the number of places in which the current through the insulation exceeds the established one.

Discrete current measurement through insulation under the influence of high DC voltage is provided by the EFHP system from MAG-ECOTESTER Company [3]. Statistical indices of the number of insulation defects 
recorded for each coil are stored on magnetic media for further analysis. This is an example of modern technological control, in which the manufacturer decides on the criteria for making technological decisions.

The goal of the work. Assessment of the guaranteed level of defect-free of insulation of enamel wires insulated with polyimide copolymers on the basis of separation:

- trend of the technological process - a significant deterministic change in the results of technological control during the technological process;

- statistical error of the technological process - the total error in the results of technological control, which is a quantitative characteristic of the random component of the stability of the technological process.

\section{Main results.}

The results of measuring the number of wire defects during the manufacturing process for 24 hours show the presence of two different periods with a continuous automated process. A significant difference in the dynamics of defectiveness changes during these periods indicates that in the technological cycle it is necessary to distinguish the periods of run-in (increased but rapidly decreasing insulation defects at the beginning of the cycle) and normal insulation (insulation defect is stable).

Consideration of the results of control of imperfection of the enamel wire as a single statistical array is possible by choosing the appropriate function for the trend, in this case exponential (Fig. 1,a). However, a significant difference in the dynamics of defect change during the periods of run-in and normal insulation causes a significant difference in the estimation of the statistical error of the control (Fig. 1,b). Therefore, to solve the set task: the development of a method for estimating the guaranteed level of insulation defectiveness, the data array is divided into a deterministic linear function $f\left(t_{i}\right)$ (trend: solid line) and a random value $\delta_{i}$ in accordance with the trend model with error (1) in [7] (see Fig. 2).

The representation of the results of the control of the imperfection of the enamel wires with two statistical sets (Fig. 2) shows that the random component (process error) in the period of normal insulation is stable and can be quantified and its average value in this case is $10 \%$ of the average number of defects for the entire period of observations. It is this quantity that is a quantitative estimate of random deviations in the technological process and should be subject to statistical control in the system for ensuring product homogeneity.

At the same time, the trend of the number of defects in the period of normal insulation, as it is determined by a deterministic function, should be subject to analysis for technologists, since it is the trend of the number of defects in the period of normal insulation that determines the criterion for the optimal duration of the continuous technological cycle. In this case, there is a weak positive trend: an increase in the number of defects $(2 \pm 1)$ defects per hour, which allows determining the time of the optimal duration of the continuous technological cycle.
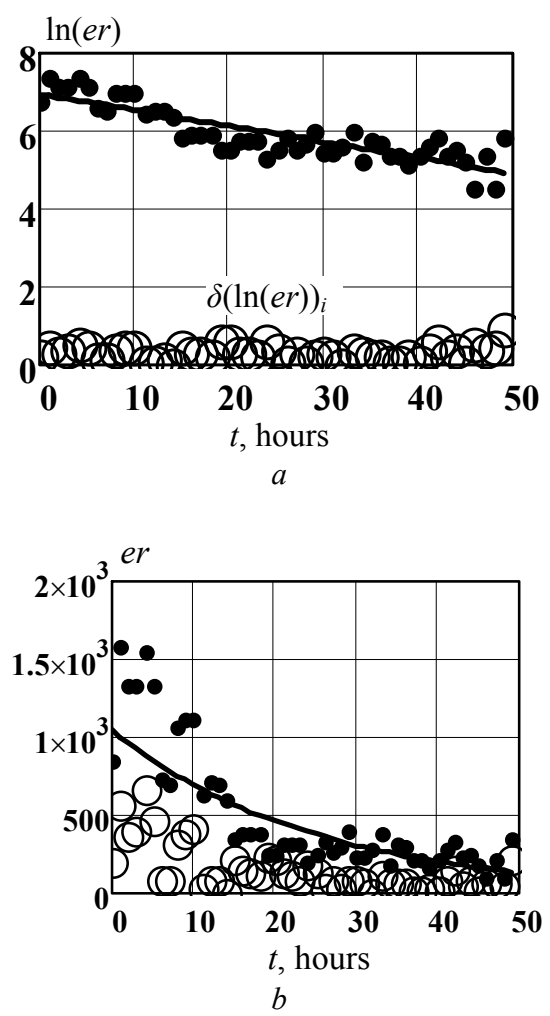

Fig. 1. Separation of the data sets on the number of defects on the coil (black dots) on - the deterministic function $f\left(t_{i}\right)$ (trend: solid line exponential function) and random value $\delta_{i}$ (empty points) using various mathematical separation procedures

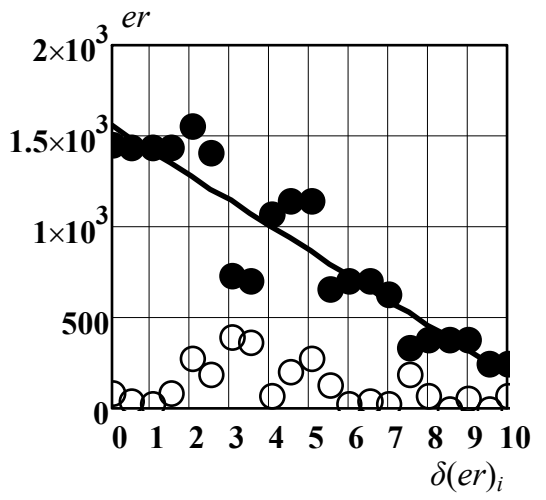

$a$

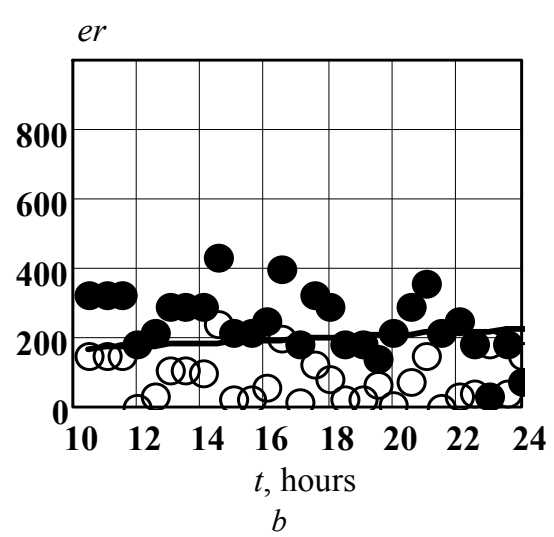

Fig. 2. Separation of data sets on the number of defects on the coil (black dots) on - the deterministic linear function $f\left(t_{i}\right)$ (trend: solid line) and random value $\delta_{i}$ (empty points) for two periods in a continuous automatic manufacturing process: the first $(a)$ run-in period and the subsequent $(b)$ normal insulation period 
A different situation exists in the period of run-in. The data in Fig. 2, $b$ show the need for technical solutions, first of all, to reduce the period of run-in. The quantitative criterion is the negative coefficient of the trend. In this case, minus $(125 \pm 7)$ defects per hour. The undoubted task of the technologist is to ensure the increase of this parameter in absolute terms by half.

The trend of a change in the values of the controlled parameter during a continuous technological cycle is characteristic not only for the defectiveness of insulation. Fig. 3 shows the results of a relative change in the diametric thickness of the enamel insulation $\delta \Delta$ in the continuous process of manufacturing 60 coils of the enamel wire.

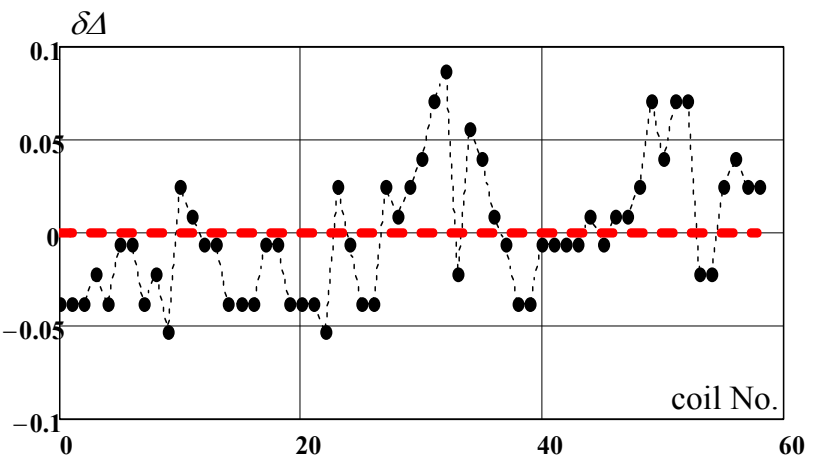

Fig. 3. The relative change in the diametric thickness of the enamel insulation $\delta \Delta$ in the continuous process of manufacturing the enamel wire ПЭЭИДХ2-200-МЭК with diameter of $0.56 \mathrm{~mm}$

It is also obvious that there is a trend, so the standard variance of a parameter includes both its random spread (statistical error) and the influence of the parameters of the deterministic component (trend). In this case, the trend of the insulation thickness is due to the technological drawing of the copper wire, which is permissible (less than $0.5 \%$ of the diameter), but affects the thickness of the enamel insulation.

Only when the trend parameters and its cause are determined (the duties of the process engineer) can the control of the variance of the controlled parameter be controlled, for this, a unified method for estimating the random component of the variance of the parameter should be used in mass production.

Dispersions of the rated parameters of the wire can be determined after it is manufactured (first of all, the variance of the breakdown voltage), therefore such control under production conditions remains largely passive.

In the EFHP system [3], the test results are displayed on-line on the monitor, the results are stored on magnetic media (system advantage). However, in production practice, these results are not used as quantitative indicators. To assess the guaranteed level of fault-free insulation, it is necessary to distinguish a random error of technological control. To this end, a unified estimation of the random component of the coil parameter dispersion should be used after the determination of the deterministic trend and the probability of the appearance of the maximum number of defects on the coil is estimated (see Fig. 4).

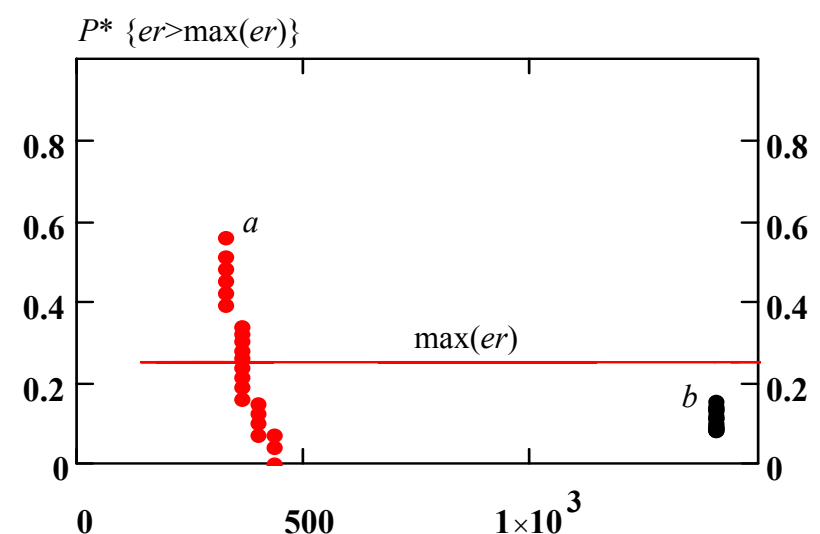

Fig. 4. Dependence of the probability of exceeding the maximum number of defects on the coil on the maximum number of defects detected (at length of $3600 \mathrm{~m}$ ) as an estimate of the guaranteed level of homogeneity of the enamel insulation, obtained by limiting the distribution of maximum values during the periods of run-in (increased but rapidly decreasing insulation defect at the beginning of the continuous technological cycle $a$ ) and normal insulation (insulation defect is stable for a long time $b$ ): it can be seen that the use of the mathematical apparatus of the limit values allows you to clearly distinguish between the technological and the running period of the normal course of the process

The mathematical procedure of highlighting the trend of the process allows you to organize an active control of the random component of defectiveness (process error). Using the statistical procedures of discrete interval models [2], the current technical decision regarding the variance of the defectiveness of each regular wire coil during the whole technological cycle is evaluated, analyzed and accepted.

For example, when controlling the diameter of the enamel wire $D$, a statistical procedure is used to estimate the maximum probability $P_{\max }$ of the output of the controlled parameter $\Delta D$ beyond the limits of the range $E \ldots \dot{E}$, defined as the sum of the corresponding probabilities of the parameter output for one-sided boundaries [4]. Moreover, the probability of a controlled parameter $\Delta \mathrm{D}$ going beyond the lower limit is taken with a minus:

$$
\begin{gathered}
P_{\max i}=\sup \left(P_{\max i}\right)-\inf \left(P_{\max i}\right) ; \\
\sup \left(P_{\max i}\right)=\left[\sup \left(\Delta D_{i \cdot 2} ; \Delta D_{i \cdot 2-1}\right]^{2} /\left\{\left[\operatorname { s u p } \left(\Delta D_{i \cdot 2} ; \Delta D_{i \cdot 2-}\right.\right.\right.\right. \\
\left.+\left[\dot{E}-0,5\left(D_{i \cdot 2-1}+D_{i \cdot 2}\right)\right]^{2}\right\} ; \\
\inf \left(P_{\max i}\right)=\left[\inf \left(\Delta D_{i \cdot 2} ; \Delta D_{i \cdot 2-1}\right]^{2} /\left\{\left[\inf \left(\Delta D_{i \cdot 2} ; \Delta D_{i \cdot 2-1}\right]^{2}+\right.\right.\right. \\
\left.+\left[E-0,5\left(D_{i \cdot 2-1}+D_{i \cdot 2}\right)\right]^{2}\right\} ;
\end{gathered}
$$

where $D$ is the wire diameter; $\dot{E}$ is the upper technological diameter limit; $E$ is the lower technological diameter limit; $\Delta D_{i \cdot 2}$ is the difference between the current diameter in sample No. $i \cdot 2$ and the average value of the diameter determined during the technological cycle $(i$ : measurement No.): 


$$
\Delta D_{i \cdot 2}=D_{i \cdot 2}-(i)^{-1} \cdot \sum D_{k}, k=1 \ldots i .
$$

Value $\left[\sup \left(\Delta D_{i \cdot 2} ; \Delta D_{i \cdot 2-1}\right]^{2}\right.$ в (3) is the square of the largest current change in diameter in the sample No. $i \cdot 2$ towards the upper technological boundary. Value $\left[\inf \left(\Delta D_{i \cdot 2} ; \Delta D_{i \cdot 2-1}\right]^{2}\right.$ in (4) is the the square of the largest current change in diameter towards the lower technological boundary.

Fig. 5 shows the results of testing the diameter $(a)$ of enamel wire with polyimide insulation in a continuous technological cycle and a control map of the maximum probability of a diameter exit beyond the limits of the range $E \ldots \dot{E}(b)$ determined in accordance with (2) - (5).

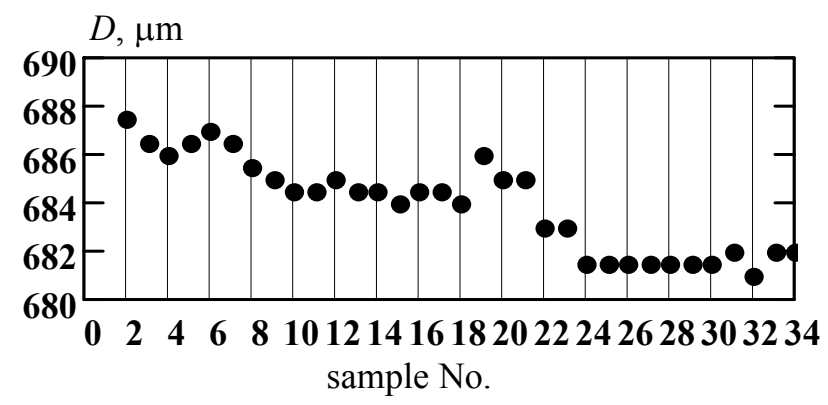

$a$

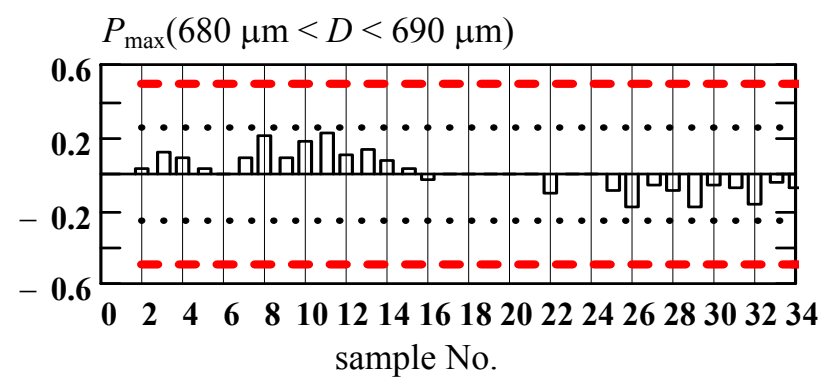

b

Fig. 5. The results of testing the diameter $(a)$ of the enamel wire in the continuous technological cycle and a control card for the maximum probability of a diameter outlet beyond the limits of the regulatory range $(b)$

Comparison of Fig. 5, $a$ and Fig. 5, $b$ indicates the informative nature of the technological control of the maximum probability $P_{\max }$ of the parameter output beyond the limits of the specified two-sided range:

1) the control chart reflects the period of technological stability during which $P_{\max }$ does not exceed the absolute value of 0.25 (dotted line) - the level of the greatest sensitivity of the control to an increase in the deviation from the mean;

2) the control chart also reflects a stable tendency to reduce the values of the control parameter, which allowed to determine the cause of the reduction trend $D$, - the increase in the drawing of the conductor during the technological cycle.

The selection of the trend of the technological process makes it possible to estimate the quantitatively non-random trend of the controlled parameter change, as a result of definable technological causes. Without such an assessment, the very concept of technological control does not make sense, since it excludes feedback in the organization of such control. In addition, the selection of the trend of the technological process makes it possible to assess the accidental error of technological control, which is caused by the total influence of many such factors, the influence of each of which can be neglected in comparison with the sum.

The need to use the procedure for dividing the array of technological control data into deterministic and random components is due to the fundamental difference between the tasks of acceptance and technological control. This fundamental difference was noted by specialists [4]. The task of technological control is to ensure the possibility of active correction of the technological process, which is impossible without the identification of definable technological causes of the trend of the controlled parameter.

\section{Conclusions.}

1. The guaranteed level of defect-free insulation of enamel wires insulated with polyimide copolymers was evaluated. The probability that the maximum number of defects fixed at length of $3600 \mathrm{~m}$ is not more than 1400 during the run-in period, and 400 defects at length of $3600 \mathrm{~m}$ during the normal insulation period, is more than $80 \%$.

2. The statistical procedure for dividing the array of technological control data into a deterministic (trend) and random component (statistical error of the technological process) was developed and used in the organization of technological control of the defectiveness of a doubleinsulated cable with polyimide copolymers. The selection of a trend makes it possible to estimate the quantitatively non-random trend of a controlled parameter change, as a result of definable technological causes.

3. The trend of the number of defects in the period of normal insulation (Fig. 2,b) is weak positive: an increase in defectiveness $(2 \pm 1)$ defects per hour. Evaluation of the defectiveness trend in this period can be used to determine the time of the optimal duration of a continuous technological cycle.

4. During the run-in period, the negative trend coefficient (in this case, minus $(125 \pm 7)$ the number of defects per hour) was used to estimate the duration of runin and to control the measures to cut it down by half.

5. The allocation of the random component allows quantifying the error of the technological process, the reduction of which requires an integrated approach, called in the world practice by the Deming method [10]. The random component (error of the technological process) during the normal insulation is stable, its average value in this case is $10 \%$ of the average number of defects for the entire observation period.

\section{REFERENCES}

1. Zelenetsky Yu.A. About the improvement of technical documentation for enameled wires. Cables and wires, 2013, no.5, pp. 19-23. (Rus).

2. Shchebeniuk L.A., Antonets S.Yu. Statistical method purpose is the reduce of quantifying defects of enameled wire. Bulletin of NTU «KhPI», 2012, no.23, pp. 166-169. (Ukr). 
3. Golik O.V. Quantifying of defects for enameled wire with two-sheeted poliimid isolation by tests by high voltage. Ukrainian metrological journal, 2009, no.1, pp. 15-18. (Rus).

4. Golik O.V. Statistical procedures for two-sided limit of a controlled parameter in the process of production of cable and wire products. Electrical Engineering \& Electromechanics, 2016, no.5, pp. 47-50. (Rus). doi: 10.20998/2074272X.2016.5.07.

5. Gnedenko B.V., Belyaev Yu.O., Solovjev A.D. Matematicheskie metody $v$ teorii nadezhnosti [Mathematical methods in theory of reliability]. Moscow, Nauka Publ., 1965. 524 p. (Rus).

6. Kuznetsov V.P. Interval'nye statisticheskie modeli [Interval statistical models]. Moscow, Radio i sviaz' Publ., 1991. 352 p. (Rus).

7. Tutubalin V.N. Statisticheskaia obrabotka riadov nabliudenii [Statistical analysis of observation series]. Moscow, Znanie Publ., 1973. 64 p. (Rus).

8. Andrianov A.V., Andrianov V.K., Bykov E.V. About the statistics of pin-hole damages of winding wires and inter-turn short-circuits in windings. Cables and wires, 2013, no.5, pp. 28-31. (Rus).

9. Technical Report IVA Laboratories: Breakdown voltage. classified: October 2007. - p. 18.

How to cite this article:

Zolotaryov V.M., Antonets Yu.P., Antonets S.Yu., Golik O.V., Shchebeniuk L.A. Online technological monitoring of insulation defects in enameled wires. Electrical engineering \& electromechanics, 2017, no.4, pp. 55-60. doi: 10.20998/2074-272X.2017.4.09.
10. Mary Walton. The Deming Management Method. Foreword by W. Edward Deming. New York: NY 10016 Copyright, 1986. $262 \mathrm{p}$.

Received 11.05.2017

V.M. Zolotaryov ${ }^{1}$, Doctor of Technical Science, Professor,

Yu.P. Antonets ${ }^{1}$, Candidate of Technical Science,

S.Yu. Antonets ${ }^{2}$, Postgraduate Student,

O.V. Golik ${ }^{2}$, Candidate of Technical Science, Associate

Professor,

L.A. Shchebeniuk ${ }^{2}$, Candidate of Technical Science, Professor,

${ }^{1}$ Private Joint-stock company Yuzhcable works,

7, Avtogennaya Str., Kharkiv, 61099, Ukraine,

phone +380 577545312

e-mail: zavod@yuzhcable.com.ua, antonets@yuzhcable.com.ua

${ }^{2}$ National Technical University «Kharkiv Polytechnic Institute»,

2, Kyrpychova Str., Kharkiv, 61002, Ukraine,

тел/phone +380 57 7076544,

e-mail: unona928@gmail.com, agurin@kpi.kharkov.ua 